\title{
Photovoltaic applications: status and manufacturing prospects
}

\begin{abstract}
Over the last two decades, advancements in photovoltaic (PV) technology have been flourishing due to the continuous flow of valuable findings. Relevant insights on recent improvements, manufacturing approaches, and various applications of PV technology are provided. Both the PV cell structure and conversion efficiency may significantly contribute to the progression of the PV system. Currently, a wide range of advanced materials and smart technologies are employed within the PV cell's architecture, improving its structure; i.e. PERC/PERL, IBC, HIT/HJT, and MWT. The applications of nanoparticles and thin film technology in PV cell structures have successfully opened new research prospects to boost PV efficiency and overcome certain limitations with the use of $\mathrm{CdSe}, \mathrm{ZnCds}, \mathrm{CdTe}, \mathrm{a}-\mathrm{Si} / \mu \mathrm{c}-$ $\mathrm{Si}$, CIS, and CIGS. Additionally, constant development in the third generation of OSC methods using $\mathrm{OE}, \mathrm{OM}$, and $\mathrm{COP}$ are conducted. The improvement of PV backsheet structures and their enhanced optical properties yielded promising results in optimizing solar radiation, reflectance, and PV cell competence. The emergence of hybrid technologies (e.g. PVTE and TPV systems) led to effective solutions for reducing excessive heat that cause deficiency to a PV cell's functionality. Overall, modelling and effectively implementing appropriate parameters (such as diode parameters, optical parameters, circuit current, circuit voltage, fill factor (FF), conversion efficiency, IR, and UV spectral parameters) contributed to the total efficiency and performance modelling of the PV system.
\end{abstract}

Keyword: PV technology; Efficiency; PV structure; PV/thin-film; Hybrid systems; Solar energy 